\title{
"BENVENUTI AL SUD” E À SALA DE AULA: UMA ANÁLISE BAKHTINIANA DE PERSONAGENS E DESLOCAMENTOS IDENTITARIOS
}

\author{
Deise Cristina de Lima Picanço ${ }^{1}$ \\ Maria Inês Carvalho
}

\section{O cinema como fonte de uma aproximação intercultural no ensino de LE}

Para compreendermos as relações interculturais provocadas pelas representações sociais que circulam na sociedade contemporânea, nos parece fundamental pensar alternativas para os problemas de inclusão/exclusão de sujeitos, temas e conteúdos.

No ensino de línguas, tanto na escola básica como na formação de professores no ensino superior, percebemos que algumas representações dificultam a consolidação de um papel formativo mais amplo para a língua estrangeira como disciplina e objeto cultural produtor de subjetividades e identidades. Muitas das representações que condicionam o modo de aproximação ou rejeição das metodologias de ensino usadas na sala de aula vêm da própria cultura escolar, que fixa conteúdos a partir de uma seleção de objetos culturais valorizados normalmente por um extrato social, sem levar em conta a diversidade identitaria dos sujeitos que compõem o campo educacional.

Nesse sentido, tanto Candau (2000) como Silva (2000) denunciam a fragilidade dos argumentos de Fourquin (em sua conferência proferida 1997) sobre "um currículo no qual as 'ciências' deveriam figurar como a representação da universalidade do conhecimento, enquanto outras disciplinas, menos 'exatas' e mais 'culturais', apareceriam como a expressão da relatividade epistemológica”. Ou seja, para Fourquin o currículo poderia ser complementarmente organizado colocando "num lado da divisória, presumidamente nobre, superior, o universalismo das ciências; no outro, presumidamente secundário, inferior, o relativismo das culturas" (Silva, 2000). No entanto, o multiculturalismo universalista de Fourquin "não é o oposto, a superação da diferença; o universal faz a diferença" quando divide enunciativamente o mundo social entre universalistas e relativistas.

Embora entendamos que as escolhas curriculares são sempre resultado de processos seletivos que, segundo Bourdieu, acabam potencializando os mecanismos de

\footnotetext{
${ }^{1}$ Universidade Federal do Paraná, Brasil.

${ }^{2}$ Universidade Federal do Paraná, Brasil.
} 
exclusão social por tratar formalmente, de modo semelhante, quem é diferente, preferimos a perspectiva menos cartesiana de Santos (1997: 122), quando acredita que "as pessoas e os grupos sociais têm direito a ser iguais quando a diferença os inferioriza e o direito a ser diferentes, quando a igualdade os descaracteriza".

Para entender estes processos excludentes como discursivos buscamos uma reflexão sobre o papel do outro no discurso, ou seja, sobre a heterogeneidade no discurso. São os pensadores do Círculo de Bakhtin que nos permitem, através da noção de vozes sociais, entendidas aqui como discursos, privilegiar a regularidade de sentido como objeto de análise. Para tanto, partimos do pressuposto de que os primeiros contatos que temos com qualquer língua e cultura, diferentes da nossa, ocorre geralmente a partir de nossa visão de mundo, ou seja, de um eixo valorativo: tanto para distanciarmo-nos delas quanto para aproximarmo-nos e até mesmo contemplá-las como sendo melhores ou piores do que a nossa língua e cultura, mais ou menos interessantes ou até mesmo mais ou menos desenvolvidas. Em seu estudo sobre identidade, Coracini (2003, p.218) mostra que "os sujeitos brasileiros são atravessados, por um lado, pelo mito do falante nativo e do estrangeiro (o que vem de fora é sempre melhor) e, de outro, por um nacionalismo exacerbado que se traduz por elogios e qualidades atribuídas a todo produto nacional”. Entretanto, ao conhecermos melhor tais línguas e culturas, a tendência é nos desfazermos desses estereótipos, ao mesmo tempo em que ocorre um deslocamento em nossa própria identidade cultual.

Esse processo, segundo Bhabha, gera não apenas o deslocamento identitario, mas também e necessariamente um processo maior ou menor de hibridização: dos discursos, das identidades, dos eixos valorativos e das posições das quais se enunciam os discursos. O conceito de hibridização vem dos estudos de Bakhtin sobre o papel do discurso do outro na constituição do sujeito, ou sobre os vários processos de apropriação da palavra alheia. Bhabha retoma esse conceito de hibridização trazendoo para o campo da diferença cultural, minimizando o papel da intencionalidade: o híbrido resultaria da interação discursiva (intersubjetiva e intercultural) independentemente da vontade dos sujeitos.

Neste ensaio, tomaremos como objeto de análise os episódios mais significativos das relações sociais que envolvem determinados personagens do longa-metragem "Benvenuti Al Sud” (2010) de Luca Miniero. Nossa intenção é discutir o papel formativo da hibridização estética das personagens em contraposição às personagens planas dos livros didáticos. Nossa aposta leva em conta o fato que elas nos permitem 
refletir sobre alguns aspectos da relação intercultural gerada no processo de ensino aprendizagem formal de línguas.

O longa-metragem de Luca Miniero nos permite essa reflexão por representar alguns dos elementos da identidade cultural construída para as personagens como tendendo a manter como únicas referências as tradições do mediterrâneo, de forma bastante etnocêntrica. O protagonista da narrativa, Alberto, representa esse centramento na ilusão de manter-se numa posição de superioridade em relação aos outros personagens. Como trata-se de uma comédia de cotidiano sobre estereótipos, rivalidades e preconceitos entre dois territórios italianos (norte e sul), o tratamento dado a esses elementos é bastante superficial, embora significativo o suficiente para provocar humor e comoção.

Para alguns autores, como Bhabha (1998: 20), que "focaliza os momentos ou processos que são produzidos na articulação das diferenças culturais", é preciso contemplar as relações sociais a partir das margens do poder constituinte, refletindo como diferentes grupos sociais, diferentes culturas se articulam através dos sujeitos discursivos, muitas vezes na defesa de seus direitos, constituindo assim novos signos identitários na relação enunciativa com o outro.

É por olhar para a enunciação como o lugar do deslocamento que entendemos os estranhamentos como parte do processo de construção de novas identidades, na relação com a outra cultura. Essa concepção de cultura e linguagem como elementos de composição da identidade, que aparece em Bhabha, se aproxima das reflexões dos autores do Círculo de Bakhtin. As ideias do círculo bakhtiniano nos permitem compreender como se dão os deslocamos de sentido na interrelação com o outro, no momento em que produzimos nossos enunciados concretos. O sujeito do círculo bakhtiniano é "o sujeito do diálogo"33 (Faraco, 2003: 60), híbrido, heterogêneo, móvel, assim como as línguas que o compõem.

Ao analisar a composição de personagens em livros didáticos (LDs), Janzen (2012) discute o efeito de sentido gerado pela composição de personagens planas na estruturação das unidades temáticas que os compõem e organizam. $\mathrm{O}$ autor parte de uma perspectiva literária de análise comparando a criação de personagens literários e didáticos. Para isso, Janzen utiliza em sua análise os conceitos de polifonia, exotopia e

\footnotetext{
${ }^{3}$ Diálogo, na perspectiva do círculo de Bakhtin, é "um dos espaços em que se dá, por exemplo, o entrecruzamento das múltiplas verdades sociais, ou seja, como um dos muitos espaços em que ocorre diálogo no sentido amplo do termo, isto é, a confrontação das mais diferentes refrações sociais expressas em enunciados de qualquer tipo e tamanho, postos em relação." (Faraco, 2003: 60)
} 
excedente de visão. Segundo o autor, é importante perceber se as vozes discursivas são plenivalentes ou se prevalece o monopólio avaliativo do autor team/autor em relação às personagens, focalizando, portanto, o aspecto da plenivalência das vozes do autor-herói na ficção e a relação autor team-personagens nos livros didáticos. Ao analisar as personagens a partir do quadro de referências da literatura, especialmente do quadro apresentado por Candido (1968) no texto A Personagem do Romance, o autor busca pontos de convergência entre as áreas da Literatura e dos materiais didáticos de LE. Segundo Janzen (2012), é possível afirmar, baseado na perspectiva de personagens planas/estáticas e na apresentação de algumas personagens representativas da concepção de ensino estruturalista-behaviorista, que há convergência entre os gêneros literário e didático em relação às personagens planas: as características gerais são bastante semelhantes, tendendo à caricatura e ao estereótipo; são orientadas pelo senso comum; estão circunscritas ao papel a desempenhar; tendem a estar desconectadas da situação econômica, social, política e da história do país; são personagens previsíveis: não mudam com as circunstâncias; são idealizadas. Como resultado da análise efetuada, o autor acredita que os LDs apontam para uma tendência homogeneizadora dos elementos estruturadores analisados. Uma tendência que pode ser vinculada a uma perspectiva estática que orienta a caracterização das personagens, que podem ser associadas à previsibilidade de comportamento e ações. Nesse sentido, as personagens estudadas permitem ao leitor/estudante pouco espaço para construir novos significados e elaborar novas construções de sentido. Assim, a possibilidade, portanto, de o aluno interagir com as personagens e os textos do LD acaba esvaziada pelas propostas elaboradas pelo autor team dos livros didáticos analisados. Segundo o autor, esta fragilidade, além de restringir o diálogo dos estudantes tanto com o LD e com a língua/cultura que estuda, pode limitar sua formação.

Em Benvenuti Al Sud, podemos encontrar alguns exemplos de diálogo intercultural no movimento que acontece na trajetória narrativa do personagem principal.

\section{Síntese da narrativa e apresentação dos personagens: capital, habitus e poder simbólico}

Diferentemente da vida, segundo Bakhtin, na arte, as reações cotidianas não são isoladas, caso a caso, ou seja, na arte há uma reação ao todo do personagem: "todas as 
manifestações particulares do herói têm significância para a caracterização do seu todo como momentos ou traços constituintes" (Bakhtin, 1990 apud Tezza, 2003: 206). O momento estético cria, portanto, suas formas, e não o contrário. Por isso, entendemos que o momento estético "é fruto de uma relação de consciências sociais, entonacionalmente carregadas - somente aí, nesse espaço de valor (social, cultural, histórico) pode-se começar a falar em obra de arte" (Tezza, 2003: 207). É nessa perspectiva que tomamos a narrativa de Benvenutti Al Sud como narrativa ficcional, como obra de arte, e analisamos os espaços volitivos de seus personagens.

Em "Cinema e a invenção da vida moderna", Charney \& Schwartz (1995 apud Adelman, 2011) discutem o fato de que numerosos estudos hoje discutem o papel subjetivo do cinema na criação daquilo que chamamos as subjetividades modernas, ou seja, na aprendizagem ou criação do que seja ser um sujeito moderno, ou no desejo de sê-lo. Para Adelman (2011: 7), o cinema "estabelece um precedente na elaboração de uma cultura (cada vez mais) visual na qual altera-se gradativamente a relação entre o real e a representação, produzindo aquilo que Charney e Schwartz chamaram de ' a crescente tendência de entender o 'real' apenas em sus representações", embora exista, segundo Lopes (2011: 165), no século XX, uma paixão pelo real, traduzida "como alternativa ao centramento da utopia no século XIX e a realização da esperada nova ordem".

Assim, considerando as estratégias narrativas cinematográficas, nos propusemos a analisar neste trabalho os movimentos dos personagens a partir da noção de hibridização, relativizando os efeitos das noções sociológicas de poder simbólico ${ }^{4}$, campo $^{5}$ e habitus $^{6}$, compreendidos como resultantes da prática social e da acumulação do capital (cultural, social, linguístico). Num primeiro momento, observaremos, durante nossa análise, alguns desses elementos presentes na composição de alguns personagens com mais ênfase do que em relação a outros. Num segundo momento, o próprio

\footnotetext{
${ }^{4}$ Para Bourdieu, em toda relação social há uma relação de poder “[...] esse poder invisível o qual só pode ser exercido com a cumplicidade daqueles que não querem saber que lhe estão sujeitos ou mesmo que o exercem" (Bourdieu, 2002: 7-8).

${ }^{5}$ Este é o "espaço social de relações objetivas", (Bourdieu, 2002: 64). O campo é um espaço onde ocorrem os embates, bem como as estratégias de ação (Bourdieu, 2011).

${ }^{6}$ Para Bouerdieu, a "disposição incorporada, geradora, criativa e inventiva, indica o conhecimento adquirido e também um haver, um capital [...] de um agente em ação (Ibid: 61). É "produto da história[...] produz as práticas, individuais e coletivas, portanto, da história, conforme aos esquemas engendrados pela história" (Bourdieu, 2011: 90). No entanto, é na prática, "lugar da dialética" (Bourdieu, 2011: 87), onde tudo ocorre, que o habitus, "sistemas de disposições duráveis e transponíveis" (Ibid: 87) cria, inventa e se modifica estrategicamente.
} 
movimento identitario dos personagens nos permite contrapor e analisar de que forma $\mathrm{o}$ processo de hibridização resultaria da interação intersubjetiva.

O filme mostra um homem de meia idade, Alberto, casado e com um filho préadolescente, que trabalha como diretor de uma agência do correio em uma pequena cidade próxima a Milão, no Norte da Itália. Sua mulher, Silvia, sonha com a ideia de viver na capital. Descobrindo que havia um posto livre, justamente em Milão, preferencialmente para deficientes físicos e, pressionado pela mulher, Alberto finge-se de cadeirante para assumir o posto. Entretanto, a artimanha de Alberto será descoberta e como castigo ele é enviado para trabalhar em uma agência no Sul da Itália, na localidade de Castellabate, uma tranquila cidadezinha nos arredores de Nápoles.

O filme de Luca Miniero, de 2010, é uma regravação de um filme francês produzido em 2008, mas que ganha contornos políticos em sua versão italiana, e nos permite trabalhar alguns elementos da interculturalidade, diferentemente das personagens planas dos livros didáticos, conforme a interpretação de Janzen. A narrativa é contextualizada em dois espaços culturais e sociais distintos: de um lado há o campo, onde está inserido o grupo extremista leghista ${ }^{7}$ (Norte da Itália) e de outro está o território dos terroni ${ }^{8}$ (Sul da Itália). O personagem Alberto representa esse grupo social leghista, que se define como uma classe trabalhadora, industrializada, bem informada, inteligente, eficiente, ágil, moderna, branca e falante da língua italiana padrão.

Por outro lado, os funcionários e clientes da agência de Castellabate representam a sociedade meridional da Itália, isto é, os terroni, definidos como uma gente matuta, ignorante, violenta, preguiçosa, vulgar, mora e que não sabe nem mesmo falar a língua italiana culta.

Em sua narrativa de comédia romântica, que abusa dos clichês, o filme nos permite contemplá-lo a partir de dois eixos pertinentes: a) os estereótipos, chamados em italiano de luoghi comuni, e b) a diferença cultural. De um modo muito perspicaz, a narrativa sobre o personagem Alberto, nosso protagonista, o coloca em situações limite em que seu habitus é confrontado com a realidade social na qual foi inserido: o primeiro estereótipo a ser desconstruído é a inteligência do próprio protagonista. Primeiramente porque Alberto finge ser um deficiente físico para lograr uma espécie de promoção, mas

\footnotetext{
${ }^{7}$ Defensor do movimento de independência do Norte da Itália (os lombardos, os emilianos e os vênetos). ${ }^{8}$ Adjetivo pejorativo que certos italianos do Norte utilizam para classificarem os italianos do Sul, como muito simples e privado de inteligência.
} 
é descoberto, e por isso será chamado de idiota $^{9}$ por sua mulher e por um colega de trabalho. Em seguida, quando Alberto é informado de que fora transferido ao Sul da Itália, ele se revela totalmente ignorante sobre a geografia do seu país, perguntando a seu colega se a cidade do Sul seria Bolonha (uma estupidez geográfica, considerando que Bologna é a capital da Emília Romagna, e está situada no Norte da Itália).

Aqui, é importante ressaltar que a Itália, como unidade narrativa imaginária (Stuart Hall), é um país marcado pelas diferenças culturais. Embora essa sua característica seja muito forte, ela é apagada pela homogeneização produzida pela representação da Itália como lugar de apenas duas identidades culturais: a do norte e a do sul. A gama de diferenças sociais, culturais, linguísticas e históricas pode ser contemplada, por exemplo, nos vários dialetos que ainda coexistem com a língua standard daquele país, o que ainda hoje é motivo de atrito entre os vários grupos sociais.

Aparentemente, é com a intenção de mostrar essa característica ambivalente (norte/sul) que o diretor Luca Miniero apresenta os principais personagens como uma rede muito bem delineada: Alberto, o personagem principal, é aquele que mais passará por transformações, saindo de sua cultura fechada, com valores fixos e resistentes à mudança (porque possui um habitus incorporado), entrará em contato com uma nova experiência sociocultural, descobrindo que suas práticas são objetivamente inadequadas às condições ${ }^{10}$ reais, especialmente naquele novo ambiente.

Vale notar que Alberto possuiria um poder simbólico institucionalizado, já que ocupa o cargo de diretor de uma agência do correio. Veste-se sempre de maneira formal, ao contrário de seus subordinados e dirige-se a eles dessa mesma forma. Desse diálogo com a nova realidade em que é inserido, ele começa, de forma inconsciente, um movimento de deslocamento identitario, que resultará numa hibridização. Esse processo contará com a atuação de outras personagens que, inicialmente, a partir de sua identidade leghista, lhe pareciam inferiores. Essa mudança, portanto, ocorre na interrelação com o(s) outro(s), embora não transcorra de modo consciente, tranquilo, pacífico, pois há muitos embates, muitos conflitos até que o personagem Alberto passe a

\footnotetext{
${ }^{9}$ pirla (Tradução nossa)

Segundo Bourdieu (2010: 85), o habitus incorporado aos sujeitos sofre mudanças que só podem ser geradas pelas condições reais de produção, ou seja, pela situação social, cultural e econômica que sustenta o conjunto das relações de poder que definem o campo de ação e o como conjunto de valores e práticas sociais. O habitus, portanto não pode ser modificado única e exclusivamente por desejo dos sujeitos que os incorporam.
} 
compartilhar alguns dos presumidos da comunidade local e passe a interagir com ela de forma distinta, sem, no entanto confundir-se com ela, duplicar-se nela.

Esses outros interlocutores que provocam essas mudanças, esses deslocamentos são especialmente Maria e Volpi, dois de seus subordinados. Bastante jovens, são os personagens mais bem (in)formados do filme. Por exemplo, eles têm completo domínio da língua italiana culta e do dialeto local, e resolvem boa parte das situações que envolvem conflitos linguísticos. Portanto, pode-se dizer que possuem uma identidade mais hibrida que a de Alberto, pois apresentam um capital cultural e linguístico que permite que atuem igualmente nas diferentes condições sociais que vivenciam. Esses dois personagens são os principais mediadores entre Alberto e a sociedade da qual fazem parte.

A mãe de Volpi, por outro lado, é uma personagem que possui uma personalidade muito forte e, assim como Alberto, resistente ao estranho, ao estrangeiro. Ela é resistente a uma aproximação com o outro, ou seja, também se apresenta como em uma identidade cultural mais fechada e mais tradicional, com fronteiras mais bem definidas. É por isso que Alberto não exerce nenhum poder (simbólico ou não) sobre ela, ou seja, além não fazer parte de sua área de atuação no mundo do trabalho, ele não consegue furar o bloqueio identitário que ela insiste, de forma inconsciente, em perpetuar. Entre ela e Alberto ocorre uma disputa de poder, mas em campos diferentes. O que torna interessante esse embate é o fato de que cada um dos personagens possui um poder simbólico próprio, que lhe é atribuído pela sociedade: ela como mãe, e ele como diretor. No decorrer da história, também essa personagem sofrerá um deslocamento - sem dúvida, pequeno comparado ao que sofrerá Alberto. No entanto, esse deslocamento produz, como efeito de sentido, um movimento de aproximação, de interlocução com alguém que apresenta uma identidade cultural bastante diversa da sua. A interlocução entre a senhora Volpi e Alberto ocorre sempre através de seu filho.

Os outros dois personagens, assim como Maria e Volpi, são funcionários do correio e também apresentam uma função de mediadores entre Alberto e o grupo local, $\mathrm{e}$, neste último caso, principalmente porque se mostram extremamente gentis e pacientes para com Alberto e os demais. No entanto, comparados a Maria e Volpi, estes personagens representam um capital linguístico diferenciado, especialmente quando falam em italiano standard, pois possuem o acento da língua local. O interessante é que são justamente sobres esses pontos linguísticos de tensão que ocorrem o estranhamento entre os três personagens, quando o diretor deseja corrigi-los, usando seu italiano culto. 
Há, ainda, entre muitos outros, um personagem que é cliente dos correios e que, estrategicamente, faz o contraponto entre o capital linguístico de que Alberto é detentor, e aquele de quem pertence à comunidade local, pois este personagem usa apenas o dialeto local. É a partir dele que Alberto se vê totalmente estranho àquele ambiente. Todo o seu capital cultural, social e linguístico, bem como seu poder simbólico mostram-se inúteis para relacionar-se com seu cliente, pois o ambiente social no qual foi gerado o seu habitus é outro.

As transformações que ocorrem durante a narrativa na composição da personagem de Alberto parece estar relacionada às questões políticas, pois o convite para rever seu habitus e mudá-lo diz respeito ao poder simbólico hegemônico do Norte da Itália, em relação ao restante do país, suas culturas e sua história. Essa narrativa crítica se revela nas atitudes dos personagens representantes do Sul, em sua relação com o diretor dos correios, proveniente do Norte da Itália, industrializada, capaz, dominante da língua culta falada italiana. Salvo a mãe de Volpi, que durante todo o filme assume uma posição de igualdade/enfrentamento em relação ao diretor, todos os outros personagens aceitam quase que incondicionalmente o poder simbólico instituído, concedido ao diretor. Nem mesmo por um pequeno instante eles questionam sua posição ou resistem à imposição de um chefe estranho ao ambiente laboral. Não são evidenciados os motivos, por exemplo, pelos quais um daqueles funcionários não poderia assumir o posto de diretor da agência do correio, ou porque deveria ser enviado alguém do Norte para assumir o cargo mais importante dentro de uma agência no Sul da Itália. O presumido que dá sustentação a isso é de que o Norte é mais desenvolvido, mais industrializado e, consequentemente, possui profissionais mais competentes, bem formados e mais capacitados para assumir postos de chefia. Não há como contraponto nesse aspecto, mas será que a narrativa pode ser suficientemente provocativa nesse sentido?

Pedagogicamente, esse longa-metragem pode ajudar-nos a refletir com nossos alunos sobre alguns desses aspectos, pois os personagens que aparecem nos LDs não se constituem como sujeitos discursivos, que dialogam com as várias diferenças culturais da realidade social. Essa tem sido uma preocupação com relação ao tratamento dos elementos culturais no ensino de LE. 


\section{Análise de alguns episódios da narrativa}

Alberto chega à cidadezinha durante a noite, debaixo de uma tempestade e quase atropela Volpi, seu funcionário, que vai ao seu encontro. Chegando ao apartamento em que deverá residir a partir de então, o diretor do correio é surpreendido com o fato de o imóvel estar totalmente vazio, e ele acredita que os móveis tenham sido roubados. Em seguida, pede a Volpi que lhe conduza a um hotel, mas este lhe diz que nenhum hotel estaria aberto àquela hora da noite e o convida para dormir em sua casa. Certamente que Alberto começa essa relação cometendo muitos equívocos, pois suas avaliações da situação concreta são permeadas por suas práticas valorativas, ou seja, por sua forma fechada e etnocêntrica de olhar o outro e a outra cultura.

No entanto, é possível ver que o primeiro estranhamento por que passará Alberto possui uma delimitação clara de fronteiras que se tornarão cada vez cada vez mais opacas. Nesse primeiro momento, o que pode ser compreendido da narrativa é que o personagem chega investido de seu poder simbólico de diretor, e avalia o outro e toda a situação imediata a partir do conjunto valores que dão sentido a esse poder. Assim, o personagem age valendo-se do poder simbólico que lhe é conferido e da posição que ocupa, e olha o outro com desdém, desprezando o contexto sociolinguístico e histórico que define a identidade linguística/discursiva do outro.

Chegando à casa de seu subordinado e anfitrião, Alberto é apresentado à mãe de Volpi e usa com a senhora o tratamento formal "Lei", que ela não entende. A mãe questiona aquele tratamento, mostrando que não o entendeu, pois não havia mais ninguém ali, isto é, uma terceira pessoa para que ele usasse aquele vocábulo, pois o pronome Lei coincide formalmente com o pronome pessoal “ela". Da mesma que com o pronome $V o i^{11}$, no uso de Lei há uma dupla função de pronome pessoal e de tratamento formal. Essa incompreensão é gerada pelas diferenças de uso que tais recursos sofrem numa Itália constituída por um mosaico linguístico, pois são dialetos diversos que, em sua maioria, são incompreensíveis entre si. Essa incompreensão se intensifica conforme as distâncias geográficas e sociais vão se ampliando, principalmente para quem vive em regiões opostas, como neste caso específico, Milão e Castellabate (próximo a Nápoles). É por isso que Alberto cometerá vários equívocos com relação à língua local,

\footnotetext{
${ }^{11}$ Na língua padrão italiana usa-se o pronome "Lei" com significado de "senhor, senhora, senhorita", no entanto, há regiões no Sul da Itália que mantém a forma latina "Voi".
} 
especialmente porque está imerso em sua identidade linguística e sofrendo e exercendo preconceitos linguísticos.

No entanto, o personagem, como já indicamos, passará a sofrer uma série de deslocamentos identitários ao longo da narrativa. Ele começa num processo que vai desde o que podemos chamar de duplicação cultural até a hibridização, passando pela plena incompreensão.

Um dos episódios de duplicação, em que se avalia o outro a partir dos seus valores, acontece quando Alberto vai tomar o café da manhã na casa de Volpi: ao deparar-se com a mesa farta, preparada com vários tipos de alimentos, inclusive com uma especialidade da senhora Volpi, o diretor avisa que pela manhã está habituado a tomar apenas uma xícara de chá, um iogurte natural e, "às vezes, uma fatia de biscoito" e não come nada mais. Com essa atitude, o diretor estaria dando uma demonstração de desconsideração com o ato de generosidade da família. Com essa desfeita, a dona da casa, mãe de Volpi, fica indignada. A senhora Volpi demonstra sua indignação usando o dialeto para se comunicar e seu filho faz o papel de mediador, traduzindo ao diretor o que a mãe lhe diz. Após algumas tentativas de se entenderem, para agradar à senhora, o diretor aceita comer algo. Nesta cena são evidenciados dois tipos de situação: primeiramente percebemos que há um estranhamento recíproco entre Alberto e a mãe de Volpi. De um lado Alberto procura duplicar o seu modo de vida em um novo contexto; e, por outro lado, a mãe de Volpi mostra que ele é estranho ao local, ou seja, à sua casa, e que ali é o território dela. Para deixar isso mais marcado ela se dirige a ele em dialeto.

O uso do dialeto é feito geralmente como uma espécie de senha, muito utilizada pelos italianos para excluir quem não é do grupo, da comunidade local, ou seja, quem não conhece aquela linguagem e todos os seus presumidos. Para Voloshinov, "apenas o que todos nós falantes sabemos, vemos, amamos, reconhecemos - apenas estes pontos nos quais estamos todos unidos podem se tornar a parte presumida de um enunciado" (Voloshinov, 1926), o que faltava a Alberto.

Podemos refletir também, sobre o momento seguinte, como um deslocamento do personagem Alberto, mediado por um presumido mais amplo, o da figura materna. No café da manhã, após titubear um momento, Alberto aceitou comer aquilo que lhe oferecia a família Volpi. No momento em que ele aceita comer a especialidade culinária da senhora Volpi, ele não apenas está sendo gentil, mas, como sujeito discursivo, dialoga com a situação imediata que se apresenta e com um presumido comum à cultura 
italiana e a praticamente todos os italianos: a figura da mãe, cultuada e reverenciada naquela cultura, principalmente pelos filhos homens (denominados "mammoni") que lhes são muito obedientes, em sua maioria. A figura da mãe exerce seu poder simbólico tanto sobre Alberto quanto sobre o filho, pois o lar é considerado o espaço onde a mãe tem o poder. Ele pode ter um cargo que lhe dá um poder simbólico sobre seus empregados, no campo do trabalho, digamos, na agência, mas não no lar, ou, melhor ainda, na família. Essa avaliação se fundamenta no fato de que também em sua casa quem controla tudo é sua mulher, mãe de seu filho.

Fato semelhante não ocorre em relação normas do ambiente de trabalho e, obviamente, os conflitos continuam a acontecer. Nesse episódio, no entanto, além dos conflitos entre os personagens que se debatem entre diferenças culturais, é possível perceber certa idealização da cidadezinha do sul, muito bem explorada por Luca Miniero, pois confronta o mundo urbano moderno, competitivo e insensível (representado por Alberto), com o mundo idealizado das pequenas cidades, onde ainda haveria espaço para as amizades desinteressadas e onde o tempo funcionaria em outra escala.

No caminho para o trabalho em seu primeiro dia como diretor da agência, Alberto e Volpi encontram algumas pessoas jogando, brincando na praça ${ }^{12}$ da cidade, em frente à agência dos correios. Volpi tenta apresentar-lhe um amigo, que oferece um café ao diretor. Alberto, continuando a caminhar, apenas responde secamente "Não, obrigado, tenho de trabalhar". Logo em seguida encontram dois de seus funcionários. Também eles querem ser gentis e perguntam se podem lhe oferecer um café de boas vindas. A reação do diretor é negativa e imediata, e só tem sentido pleno na narrativa se contextualizada e conectada com as cenas anteriores e as posteriores às do café servido na casa dos Volpi.

Alberto encarna então o chefe mal humorado e exigente, e critica o ambiente e todo o grupo, questionando-os sobre o fato de que "neste lugar não fazem outra coisa a mais do que beber café, já são nove horas, vamos trabalhar". É neste momento que chega Maria, também ela desenvolta e simpática, e o cumprimenta. Alberto nem mesmo lhe responde o cumprimento e diz apenas que ela estava atrasada.

Neste campo, o do trabalho, Alberto passa de espertalhão a funcionário idiota, e depois a chefe insensível e mal educado. O personagem torna-se, naquele outro

\footnotetext{
${ }^{12}$ É pertinente notar que, no filme, a praça tem um significado muito importante para a vida social da cidade, é onde o povo se reúne para conversar, brincar e se divertir.
} 
território, o diretor eficiente, exigente, que deve dar o exemplo. No entanto, está fora de seu campo sócio cultural e histórico, onde há outras regras que ele, agarrado às suas práticas sociais, não percebeu. Isto é, ali, ele é o estrangeiro, suas regras não funcionam, as estratégias são outras.

Com essa mudança de papel (de espertalhão a chefe exigente), o personagem de Alberto encarna várias representações do mundo do trabalho, das culturas que compõem o mosaico de vozes e a dicotomia norte-sul italiana. Acostumado que estaria com as disputas que ocorrem no ambiente laboral, onde não haveria espaço para a amizade, para a solidariedade entre colegas de trabalho, Alberto demora a perceber que está em outro registro sociocultural.

Novamente, no entanto, Luca Miniero nos apresenta outro presumido mais amplo: todos reconheciam e respeitavam o poder simbólico que fora imposto/concedido a Alberto, fato esse comprovado pela forma com que o denominavam, sempre como "diretor", pois nunca o tratavam pelo nome, tanto os funcionários quanto os clientes. $\mathrm{O}$ presumido aqui seria o de que os italianos, em sua grande maioria, são bastante formais, um traço cultural um tanto estereotipado, bastante evidenciado durante o filme. No entanto, o personagem Alberto sobrepõe esta formalidade relacionada ao poder simbólico à posição hierárquica com que olha a comunidade da cidadezinha para a qual fora transferido como castigo. Dessa forma o personagem sobrepõe o cargo à posição de onde vê as pessoas, sua cultura e seus valores. Fechado e hierarquicamente superior aos outros, à outra cultura, busca apenas manter seu status quo.

Entretanto, o personagem, que já se deslocou fisicamente, também passa a deslocar-se interiormente, pois percebe-se estranho ao local. O momento da narrativa em que Alberto sente essa descontextualização sociocultural e linguística, por desconhecimento dos presumidos daquele grupo, ocorre quando, estando ele e seus funcionários na agência, chega um cliente ao guichê: um de seus funcionários todo solícito e gentil o escuta, e busca entendê-lo. No entanto, incomodado com a situação e porque, aparentemente, em sua concepção, a situação não se resolvia eficientemente, o diretor intervém, dizendo ao funcionário que ele mesmo resolveria a questão. Novamente Alberto age apenas duplicando o conjunto de práticas e valores de sua cultura, buscando reconhecer na cultura do outro, aquilo que lhe é correspondente. Alberto se dirige ao cliente usando o italiano standard acreditando que com isso resolveria a situação de forma satisfatória. No entanto, seu capital linguístico, que era funcional no contexto social de onde vinha, não o era naquele de seu interlocutor, por 
isso suas tentativas de resolver o problema mostram-se totalmente ineficientes, patéticas, pois o cliente não falava italiano standard e não o compreendia. Além da diferença linguística havia também diferenças valorativas.

Mesmo com toda a proibição realizada pelo regime fascista das década anteriores, os dialetos locais são constituintes da Itália e permanecem vivos na realidade social de várias localidades daquele país, e também aqui no Brasil. Por esse motivo, o personagem é colocado numa situação muito comum entre os italianos, embora negado pela maioria deles: foi assim que o diretor necessitou da hábil mediação de Maria, sua funcionária, para traduzir o que dizia do cliente.

Ao perceber-se ineficiente e estranho no ambiente laboral que lhe fora sempre muito compreensível, o personagem encarna uma transformação, típica das personagens da ficção cinematográfica, mas que também nos serve para discutir a forma homogeneizadora e tradicional com que os italianos são retratados na maior parte dos nossos livros didáticos. Em nenhum deles, provavelmente, os dialetos são apresentados como um espaço de conflito, onde valores e visões de mundo são confrontados. Há apenas diferenças linguísticas, sistêmicas, formais. Eles são mostrados como curiosidades da cultura italiana, silenciando um conflito social, político e econômico que sobrevive às tentativas de standartização da língua.

É interessante que, na narrativa, Alberto passe agora a encarnar o personagem deslocado, desajeitado, descontextualizado. Aproveitando o horário de almoço, costume mantido firmemente na cidade, dois de seus funcionários jogam bola com outras pessoas, dentre as quais algumas crianças, em frente à agência, e por descuido a bola entra porta adentro, parando na mão do diretor. Esse fato corriqueiro para os habitantes da localidade torna-se também motivo de desentendimento e conflitos.

O personagem sente-se instado a moralizar a agencia e define que o horário de funcionamento deveria ser das 8:00 às 13:00; das 13:00 às 14:00 pausa para o almoço e fechamento às 17:00, acrescentando ironicamente "também aqui é Itália, não é mesmo?". Este comentário tem pleno sentido para aqueles que conhecem um presumido, defendido por determinados grupos separatistas da Itália, que sustentam que o Sul não seria Itália, mas África.

Na mesma linha moralizante, o diretor sustenta que, por motivo de segurança, pediria aos superiores verba para instalar câmeras de vídeo dentro e fora da agência, bem como portas e janelas blindadas. Outra vez Maria intervém, querendo mostrar-lhe que ele estava completamente equivocado, pois sua visão de mundo, seus valores não 
eram adequados para a nova realidade na qual ele estava inserido, a começar pelo horário das pessoas da cidade: de manhã as pessoas iam sempre ao correio entre 12:00 e 13:00, porque tinham outras coisas para fazer nos outros horários, e à tarde era igual, ninguém aparecia na agência antes das 16:00, assim sugeriu que a agência ficasse aberta até as 18:00. Quanto à segurança, disse a funcionária, "nunca houve um roubo na cidade, todos se conhecem”. No entanto, Alberto a ignora, firme em suas convicções. Outro funcionário tenta convencê-lo, mas é interrompido pelo diretor, que diz não entendê-lo e exige que esse funcionário dirija-se a ele, em "língua italiana". Há um preconceito claro com relação ao acento do funcionário, pois ele não estava falando em dialeto, usava a norma culta italiana, com acento meridional. Esse detalhe tampouco seria compreendido por um estudante que tivesse contato com as variantes da forma idealizada e superficial dos livros didáticos.

Nem bem passado esse outro momento de estranhamento, realizado pela duplicação valorativa, ao sair de seu trabalho para ir embora, seus funcionários estão acompanhando uma partida de bilhar na praça e o chamam. Um deles está com um taco na mão e vai ao seu encontro, junto com o outro funcionário, e neste momento chega também Volpi chamando-o em alta voz. Acreditando que a comunidade é violenta e os funcionários estão contra ele, Alberto põe-se a correr desesperadamente, escadas acima, por entre os corredores das casas e seus funcionários vão atrás dele, tentando alcançá-lo e gritando "diretor, diretor".

Para desvencilhar-se deles, Alberto dá um chute em um dos funcionários e entra abruptamente no apartamento. Nesse momento, surpreende-se ao ver que Maria estava esperando-o e que seu apartamento estava parcialmente mobiliado. Os outros funcionários entram em seguida, e ele, ainda surpreso, pergunta de onde vieram os móveis. Maria respondeu que "cada um tinha colaborado com algo". Ainda que de forma caricata a narrativa cinematográfica conta essa história fazendo o contraponto entre a realidade móvel e a representação, portanto é importante mostrar que o movimento sociocultural em direção ao outro ocorre de forma quase unidirecional: dos funcionários ao diretor, que se surpreende: "mas vocês nem me conhecem!"

\section{Considerações finais}

Como Benvenuti Al Sud caracteriza-se como uma comédia do cotidiano, para que a narrativa funcione é necessário que os deslocamentos identitários sejam evidenciados, 
o que na vida real e concreta da relação intercultural ocorre de forma quase imperceptível aos sujeitos e a ambas as culturas, pois cada ato no cotidiano tem um sentido em sua eventicidade, diferentemente da narrativa estética, em que cada ato é um elo no todo da narrativa. No filme, uma representação daquilo que seria uma desconstrução parcial dos estereótipos compartilhados por Alberto, ocorre quando ele abre a janela de seu apartamento e vê a amplitude do mar mediterrâneo, do horizonte que se desvela. No olhar da personagem, o mar significaria um mundo novo que é ao mesmo tempo um reconhecimento e uma descoberta. Assim, também a natureza, ou melhor, como ele a vê, faz parte desse movimento de aproximação e ressignificação daquele contexto social: quem resistiria a uma visão panorâmica maravilhosa do azul turquesa do mar do sul da Itália intacto?

Se Alberto é uma representação do deslocamento identitário, o mesmo não acontece com igual intensidade com os funcionários de sua agência. Descoberta a senha necessária para o movimento de aproximação, o respeito e a cordialidade entre os membros daquele grupo, Alberto passaria a agir também como mediador. Parece que aqui podemos perceber o desejo de Luca Miniero de ver uma Itália unida, compreensiva com as diferenças culturais (que fazem parte daquela realidade), mas acima de tudo busca preservar a italianità. O longa-metragem, objeto de cultura atravessado por várias vozes sociais, rende-se ao discurso de que no fundo existe uma italianità. Mostra a diferença a partir de um viés valorativo, uma posição axiológica, simpática aos italianos do Sul, que coloca em cheque o modo como o mundo moderno, desenvolvido e civilizado do Norte olha o restante da Itália. Ainda que de forma também caricata, será que o filme põe o dedo na ferida e mostra que a realidade social é bem mais complexa e constituída pela diferença cultural, social e histórica, não pela homogeneidade? Há na relação com o outro, nos momentos da interlocução,no exato instante da enunciação, as brechas para os contra-discursos, para a construção de novos sentidos ou se revestem os estereótipos com outras roupagens? Por exemplo: ao apresentar a italianità através da disputa entre os produtores de queijo reforça-se o estereótipo ou criam-se novos sentidos para as identidades locais? Procurando ser gentil com a mãe de Volpi, Alberto apresenta a ela um queijo gorgonzola que, de imediato, ela rejeita, degustando-o, no entanto, por intermédio do filho. É dessa forma simplificada que o filme (re)estabelece fronteiras no interior do diálogo intercultural. No entanto, vendo-o como narrativa ficcional, objeto de cultura e objeto pedagógico, o filme pode transformar-se em espaço de construção de sentido, de construção de (novos) conhecimentos. Na maior parte dos 
livros didáticos os tipos de queijo são apresentados em seus formatos e localizados geograficamente, mas além de seu valor como alimento, não exploram seu valor social, histórico, linguístico e, obviamente, gastronômico (que não é o nutricional ou mercadológico).

Essa identidade hibrida que Alberto apresenta no decorrer da narrativa também aparece em outras cenas, como quando ele se mostra incomodado porque Volpi demora tanto para retornar à agência quando saía para entregar as correspondências, e, geralmente, em seu retorno estava ligeiramente embriagado. Ao decidir ir junto com o funcionário, Volpi questiona o que fariam se alguém lhes convidasse para um café: “diremos um não milanês", responde Alberto. "E como é um não milanês?”, pergunta Volpi. "Um não categórico", responde o diretor. Alberto irá descobrir que a cordialidade do povo local era mais persuasiva e eficaz do que o não milanês, pois como o diretor não aceitava tomar um café, os habitantes ofereciam-lhes "suco local" que, de suco, tinha apenas o nome: na realidade era uma bebida alcoólica muito conhecida na Itália, principalmente na região Sul, denominada limoncello.

Assim, ainda que pareça simpático aos acolhedores moradores da pequena cidade do Sul, a narrativa de Luca Miniero reforça estes estereótipos, marcados pelas atitudes de muitos personagens: a religiosidade, a generosidade, a hospitalidade, mas também simplicidade, a falta de disciplina e de sofisticação.

$\mathrm{Na}$ narrativa, a atitude de acolhimento da comunidade local funcionou como um catalizador para o movimento de hibridização do personagem. Portanto, como arena de dizeres, a narrativa cria em torno de seus personagens um espaço de enunciação, um local de hibridização cultural, definida por Bhabha como sendo "um processo para entender ou perceber o movimento de trânsito ou de transição ambíguo e tenso que necessariamente acompanha qualquer tipo de transformação social” (Bhabha, 2002 (b) apud Souza, 2004).

Essa percepção de movimento dificilmente pode ser percebida em personagens de livros didáticos. Até mesmo as contradições da narrativa, que se propõe refletir sobre a territorialização da italianità, mas que reitera certos estereótipos culturais torna-se mais produtiva para o trabalho de ensino-aprendizagem de línguas como construção de sentidos e não apenas de reconhecimento de um novo código linguístico. 


\section{Referências}

ADELMAN, Miriam [et al.] ( Orgs). Mulheres, Homens, olhares e cenas. Curitiba: Editora da UFPR, 2011.

BHABHA, H. K. O local da cultura. Belo Horizonte. Ed. UMG, 1998.

BOURDIEU, P. Os três estados do capital cultural. In: NOGUEIRA, M. A.; CATANI, A. Escritos de Educação. 11 ${ }^{a}$ Ed. Petrópolis: Vozes, 2010, p.71-79.

. O senso prático. Trad. Maria Ferreira. Petrópolis: Vozes, 2011.

. A gênese dos conceitos de habitus e de campo. In BOURDIEU, P. O Poder Simbólico. 13 ${ }^{\mathrm{a}}$ Ed. Rio de Janeiro: Bertrand Brasil, 2002.

CANDAU, Vera Maria. O currículo entre o relativismo e o universalismo: Dialogando com Jean-Claude Forquin. IN: Educação e Sociedade, Campinas/SP: UNICAMPI, ano XXI, no 73, Dezembro/00. Disponível em http://www.redalyc.org/articulo.oa?id=87313697006

CORACINI, Maria Jose. A celebração do outro na constituição da identidade. IN: Organon, Porto Alegre, RS: UFRGS, 2003. Disponível em $<$ http://seer.ufrgs.br/organon/article/view/30024>

FARACO, C.A. Linguagem \& Diálogo: as ideias linguisticas do círculo de Bakhtin. Curitiba: Criar Edições, 2003.

JANZEN, Henrique Evaldo.Concepção bakhtiniana de literatura e a análise de personagens nos livros didáticos de LEM/. Bakhtiniana: Revista de Estudos do Discurso, v. 07, p. 107-124, 2012.

LOPES, Denilson. Novos cotidianos, novas familias. IN: ADELMAN, Miriam [et al.] ( Orgs) Mulheres, Homens, olhares e cenas. Curitiba: Editora da UFPR, 2011.

SANTOS, B. de S. Uma concepção multicultural de direitos humanos. Lua Nova, n. 39, 1997.

SILVA, Tomaz Tadeu. Currículo, universalismo e relativismo: Uma discussão com Jean-Claude Forquin. In: Educação e Sociedade, Campinas/SP: UNICAMPI, 2000, vol. 21, no. 73. Disponível em http://dx.doi.org/10.1590/S0101-73302000000400005

SOUZA, Lynn Mario T. Menezes de. Hibridismo e Tradução Cultural em Bhabha, In: ABDALA JUNIOR, Benjamin (org). Margens da Cultura: mestiçagem, hibridismo \& outras misturas. São Paulo: Boitempo, 2004. P.113-133. Disponível em: http://www.osdemethodology.org.uk/texts/lynnbhabha.pdf. Acesso em: janeiro de 2014.

TEZZA, C. Entre a prosa e a poesia: Bakhtin e o formalismo russo. Rio de Janeiro: Rocco, 2003.

VOLOCHINOV, V. N.; BAKHTIN, M. Discurso na vida e discurso na arte: (sobre poética sociológica). Tradução de Carlos Alberto Faraco e Cristóvão Tezza [para fins didáticos]. 1926. Versão da língua inglesa de I. R. Titunik a partir do original russo. 